\title{
Times getting tough for an ex-giant
}

\section{Jena, Germany}

Just last month, it seemed as if Jenoptik Carl Zeiss JENA, the world-renowned eastern German optical company, would survive the rigours of German unification. Facing a takeover by its western German counterpart, Zeiss-Jena had been threatened with virtual shutdown and the scrapping of many of its lines of microscopes, telescopes, lasers and other scientific equipment. Then, on 6 March, the German Land of Thuringia (where Jena is located) stepped in and offered to take ownership of the company under a government-sanctioned agreement that would even absolve Zeiss-Jena of its DM1,350 million (about $\$ 800$ million) debt.

Now, however, it seems as if the news may have been too good to be true. After apparently taking a closer look at Zeiss-Jena's disastrous financial situation, Thuringia announced on 27 March that it needed more time to negotiate details of the agreement.

The Land's takeover of the company, originally scheduled for 1 April, has been postponed until at least 31 May, raising the possibility that Thuringia may not be able to rescue Zeiss-Jena after all.

For scientists, particularly those in developing countries and the former Eastern Bloc countries, the troubles of Zeiss-Jena have a special significance. In the West, the company has a solid reputation for making precision measuring devices and certain optical instruments such as microscopes, binoculars and aerial cameras - the latter being a field where the company commands a large part of the US market. And in the former Soviet bloc, Brazil and elsewhere in the developing world, Zeiss-Jena had a virtual monopoly on high-technology optical equipment. It has, for example, built more scientific telescopes in the one- to two-metre range than any other company in the world, producing 12 telescopes (mostly for institutes in the Soviet bloc) in the past 30 years.

But the success or failure of Zeiss-Jena will affect more than just the supply of certain types of scientific instruments. In many ways, the way in which the company's predicament is resolved will be a test case for eastern German industry in general. After all, the optical company has a respected reputation, a skilled workforce and a good product. If it cannot compete successfully in the free market, how can other international businesses in the former Communist country hope to do better?

Zeiss-Jena has a distinguished history going back to 1845 , when Carl Zeiss founded his original microscope factory in Jena. For 100 years the company grew and prospered, but, at the end of the Second World War, it, along with Germany, was split in two. In June 1945, departing Allied forces took more than 100 executives and technicians out of Jena and settled them in a suburb of Stuttgart.
There the Zeiss employees founded Carl Zeiss-Oberkochen, which by 1989 had grown to 31,000 workers and net sales of DM4,500 million ( $\$ 3,000$ million).

Zeiss-Jena prospered too during that time, but by a different path. Set up as a Volkseigener Betrieb, or people-owned company, it moved into producing cameras, eyeglasses and, ultimately, computer chips, in addition to its core business of microscopes, telescopes and other optical devices. By 1989 , it had 70,000 workers and an annual turnover of 3,900 million East German marks (equivalent to $\$ 2,600$ million at the official - unrealistic - exchange rate).

Everything changed, however, with the unification of the two Germanies. The East German government had subsidized ZeissJena - as it had many other exporting com-

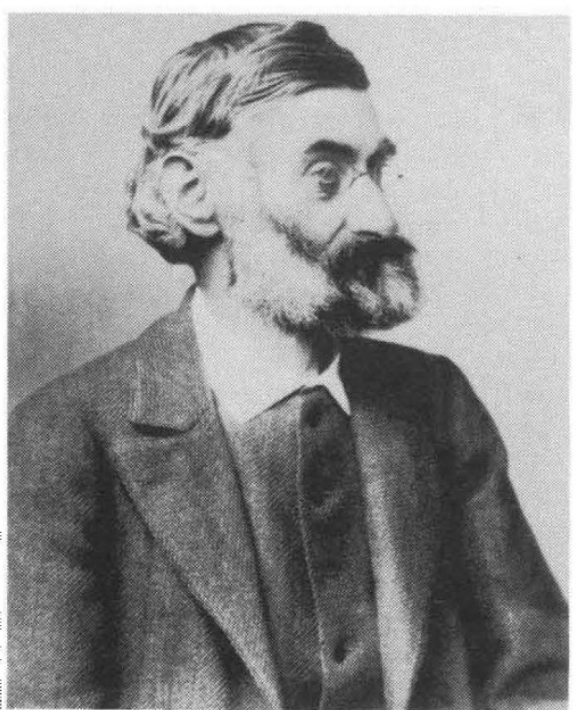

Physicist Ernst Abbe, who shaped the company in its formative years.

panies - by guaranteeing that its products would be bought at unrealistic prices. When East Germany carried out a currency reform in July 1990, making two East German marks equal to one West German mark, Zeiss-Jena became unprofitable overnight. Suddenly the Soviet bloc, which had accounted for 65 per cent of the company's market, could no longer pay for Zeiss-Jena products because the company demanded hard currency instead of 'transfer roubles', the artificially priced money of the Soviet Union and its satellites. (Many Soviet and Eastern European scientists miss the old arrangement just as much as does Zeiss-Jena, because, now that they can no longer pay in roubles, their supply of optical equipment has dried up, with no replacement in sight.)

In response to the economic pressures, Zeiss-Jena has dropped its camera and chip sidelines and reduced its work-force from 70,000 to 27,000 workers. And the management has developd a blueprint for further rationalization, keeping just 10,000 workers.

Against this background, the two Zeiss siblings began moving cautiously towards a merger. In May and November 1990, they signed agreements to work cooperatively toward reunifying Carl Zeiss. But when rumours circulated that the western German company would release all but 2,700 workers, the atmosphere turned unpleasant. On 13 February, 20,000 workers demonstrated in Jena, demanding job security.

Three weeks later, the Land of Thuringia offered to take over the company from the governmental trust body that had been set up by Bonn to refinance and stabilize eastern German industry and which had overseen the negotiations with Zeiss-Oberkochen. But Thuringia suddenly backed off - apparently when it realized that it could not pay for the company's continuing losses, which financial analysts estimate could eventually reach DM2,000 million.

So now reunification with Zeiss-Oberkochen has been given another chance. The trust body is conducting one more round of negotiations, and these include four parties: the two Zeiss companies, Thuringia and Baden-Württemberg, the Land in which Oberkochen is located.

But Zeiss-Jena is not just sitting back and waiting to see who will end up in control. Instead, it is scrambling to carve out a niche on the Western market, primarily with highly specialized projects that emphasize its scientific strengths. For example, it is building a mirror for an experimental six-legged optical telescope; the designers turned to Zeiss-Jena when they could not find a Western company to build the mirror to the necessary specifications (see Nature 341, 177; 1989).

In a project for the European Space Agency (ESA) technology centre in Nordwijk, the Netherlands, Zeiss-Jena is developing highly precise testing equipment for satellite-based lasers. The lasers will be used to transfer data from a satellite in a low-Earth orbit to a satellite in a higher, geostationary orbit. The laser beams, which carry 65 megabytes of information per second, have to be accurate within a range of 200 metres over a distance of $45,000 \mathrm{~km}$.

A visit to the Zeiss-Jena research laboratories shows a company trying furiously to pull itself up by its bootstraps. A satellite dish antenna has replaced the red star atop the corporate headquarters in central Jena, but the workers know that competing in the West will take much more than that. "We had to develop from scratch technologies that already existed in the West because we weren't allowed to buy them," says Klaus Mütze, former director of research at Zeiss-Jena. "A lot of our scientists, especially the older ones, are having trouble making the transition."

No one doubts, however, that parts of the company are worth preserving. "There are brilliant people at Zeiss-Jena who have rightfully retained the hard-earned German 
reputation for precise work," says one Western researcher, expressing a commonly held view. If Zeiss-Jena were to go under, he adds, it would be "the end of an era".

Outside analysts say that the worst can indeed be avoided. One analyst from the US consulting firm SRI International, which is developing a concept for the reconstruction of the optoelectronics industry in the Jena region, says that the ability to do such hightechnology projects as the hexapod telescope distinguishes Zeiss-Jena from eastern German companies in other fields. This may help buy time for the company, he says. Assuming - and this is the key assumption that sufficient financial support and retraining of workers is provided over the next five years or so, the analyst says he sees an "excellent chance" for Zeiss-Jena to survive, either as one company or a number of smaller ones.

Zeiss-Jena managers say their strategy includes plans to develop or expand in new

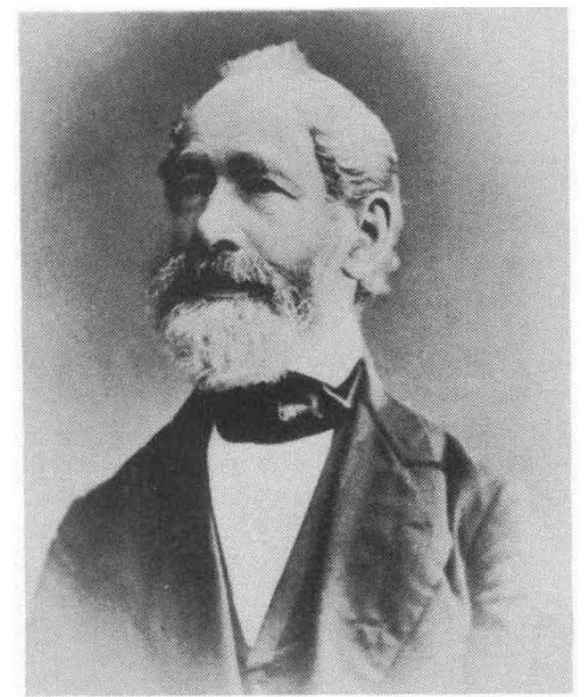

Carl Zeiss, founder of the optics company, pictured in about 1885 .

areas, such as lasers for medical and measuring applications, optical coatings and devices and digital image-processing, in addition to trying to expand sales to the West in Zeiss's traditional strengths - predominantly microscopes and measurement technology.

Whatever happens, Zeiss-Oberkochen is likely to play a major role in its long-lost sibling's future. The company was very annoyed at being shut out of the original talks between Thuringia and the trust body, and now it says that, if necessary, it is ready to go to battle over Zeiss-Jena. If the company is given to Thuringia, then Zeiss-Oberkochen may well go to court to determine who has the rights to the Zeiss name, says Manfred Berger, a spokesman for the western German company. "But we're still assuming we'll find a mutually acceptable solution."

Until then, Western researchers and Zeiss employees will be watching closely to see if capitalism can do in less than two years something that even 45 years of Communism could not achieve: destroy the historic Carl Zeiss-Jena.

Steven Dickman

\section{Tough times in South Africa}

\section{Johannesburg}

THE South African research councils and the universities are faced with their toughest financial constraints ever, following the budget recently delivered to parliament by Minister of Finance Barend du Plessis. The budget was characterized by large increases in spending on police (to attempt to curb civil unrest) and foreign affairs (to establish new missions abroad in the wake of the thaw in South Africa's foreign relations), but little or nothing more for research.

Despite an increase in government spending of 14 per cent (roughly in line with inflation), four of the five research councils suffered cuts in their parliamentary grants. The 1991-92 allocations to the councils were as follows (with percentage increase or decrease in brackets):

- Council for Industrial and Scientific Research (CSIR), R207m (£44.23m)

$(-2.4 \%)$;

- Foundation for Research Development (FRD), R109m ( $£ 23.29 m$ ) (-4.8\%);

- Human Sciences Research Council (HSRC), R61m (£13.03m) (-1.9\%);

- Council for Mineral Technology (Mintek), R52m (£11.11m) (+2.7\%);

- Medical Research Council (MRC), R39m $(£ 8.33 \mathrm{~m})(-5.0 \%)$

The variation in allocations can be explained by the fact that the councils are funded through different government departments, which fared differently at the

\section{ANIMAL RESEARCH Challenge on testing}

Washington

As the battle lines of the animal-rights struggle shift, animal toxicity tests such as the LD-50 and Draize procedures have become the subject of challenges across the United States and in Congress. Last month, both the California and Vermont state assemblies passed bills outlawing skin-irritation and ocular (including Draize) testing on animals in the state. The bills will now be voted on in their respective state Senates. Since 1987, the number of states that have considered such legislation had tripled, to nine in 1990 . Six are already debating animal-testing bills this year, and more are expected before the end of the year.

In the US Congress, Senators Harry Reid (Democrat, Nevada) and Barbara Boxer (Democrat, California) intend to introduce bills to restrict or outlaw animal testing for cosmetics and household products. Although both have tried and failed to pass such legislation in the past, research advocates consider the new bills to be a serious threat. "The trend is obvious," says Barbara Rich, executive vice-president of the National Association for Biomedical Research. "Toxicity testing will be the big issue this session". Christopher Anderson hands of the Treasury. The cuts inflicted on the CSIR and MRC were lower than those in their funding departments' budgets: Trade and Industry and Health received cuts of 25.3 per cent and 12.1 per cent respectively. Mintek received its increase despite a 5.8 per cent cut in the budget of the Department of Mineral and Energy Affairs. The remaining councils, the FRD and the HSRC, along with the universities and national museums, are funded through the Department of National Education, which received a 1.6 per cent increase in its budget. The universities received exactly the same subsidies as last year, but at least negotiated their way out of a cut (see Nature 348, 183; 1990). The national museums, including the largest natural history museum, have also suffered severe cuts for the first time.

The CSIR, which is responsible for technologically orientated research conducted by its own laboratories, raised 46 per cent of its budget last year by contract work done for the private sector and government departments. According to its president, Dr Brian Clark, it hopes to increase this figure to 51 per cent this year, providing for an overall planned growth in income of 8 per cent. The FRD, MRC and HSRC are responsible for the provision of studentships, as well as the funding of research at universities, technikons and museums, so this sector is set to suffer most.

Michael Cherry

\section{The end for monkeys}

\section{Washington}

GoverNMENT scientists experimented on and killed two of the last four remaining 'Silver Spring monkeys' last week after a last-minute legal battle that reached the US Supreme Court.

Officials at the National Institutes of Health (NIH) said the animals were dying of complications from previous injuries. Rescued by activists in 1981 from a laboratory in Silver Spring, Maryland, the monkeys have been a cause célèbre for the animal rights movement and the symbolic poster children of antivivisectionism.

Last week, the activist group People for the Ethical Treatment of Animals appealed to the Supreme Court after failing in lower courts to gain a restraining order so that the poor health of the animals could be confirmed by an independent veterinarian. Although the high court temporarily halted the experiment for one day, it permitted the killing of the monkeys after NIH said the animals were in pain, had ceased eating and would soon die. NIH researchers placed the animals under "terminal anesthesia" before examining their brains for signs of neural reorganization as an adaptation to injuries suffered in the original Silver Spring experiment. 